\title{
Evaluation of the Adhesion Strength of Diamond Films Brazed on K-10 Type Hard Metal
}

\author{
Sérgio Ivan dos Santos ${ }^{\mathrm{a} *}$, Carlos Alberto Medeiros Casanova ${ }^{\mathrm{b}}$ \\ Cleiton Rodrigues Teixeira ${ }^{\mathrm{b}}$, Naira Maria Balzaretti ${ }^{\mathrm{a}}$, João Alziro Herz da Jornada ${ }^{\mathrm{a}, \mathrm{c}}$ \\ ${ }^{a}$ Av. Bento Gonçalves, 9500 Campus do Vale - Instituto de Física - LAPMA \\ UFRGS, C.P. 15051, 91501-970 Porto Alegre - RS, Brazil \\ ${ }^{\mathrm{b}}$ Depto. Materiais de Construção - FURG, Rio Grande - RS, Brazil \\ 'INMETRO, Xerém - RJ, Brazil
}

Received: January 29, 2003; Revised: November 10, 2003

\begin{abstract}
The coating of cutting tools with diamond films considerably increases the tool performance due to the combination of the unique tribological properties of diamond with the bulk properties of the substrate (toughness). The tool performance, however, is strongly related to the adhesion strength between the film and the substrate. In this work our main goal was to propose and to test a procedure, based on a tensile strength test, to evaluate the adhesion strength of a diamond wafer brazed on a hard metal substrate, taking into account the effect of the brazing temperature and time. The temperature range studied was from 800 to $980{ }^{\circ} \mathrm{C}$ and the brazing time ranged from 3 to $40 \mathrm{~min}$. The obtained results could be used to optimize the costs and time required to the production of high performance cutting tools with brazed diamond wafers.
\end{abstract}

Keywords: brazing, diamond, CVD, adhesion strength, cutting tool

\section{Introduction}

Diamond has unique tribological properties that are very useful for technological applications. In the field of machining of very abrasive non-ferrous materials, for instance, the performance of diamond tools is outstanding ${ }^{1,2}$. Polycrystalline diamond inserts (PCD) on tungsten carbide substrates are widely used in industry. They are produced by high pressurehigh temperature (HP-HT) sintering of diamond grains with a metallic binder, usually cobalt. The direct deposition of a thin diamond film by the CVD (Chemical Vapor Deposition) technique on a tungsten carbide tool surface is an alternative way of coating cutting tools with planar and non-planar shapes. To enhance the adhesive strength between the diamond film and the substrate, a pre-treatment of the tungsten carbide is required in order to decrease the deleterious effect of its cobalt content on the diamond deposition ${ }^{1}$. The surface roughness of the growing side of the diamond film will be transferred to the machined workpiece and, for some applications, the polishing of the diamond film will be required.

Brazing a thick CVD diamond wafer $(\sim 500 \mu \mathrm{m})$ over a

*e-mail: ssantos@if.ufrgs.br

Articles presented at the XV CBECIMAT, Natal - RN, November de 2002. tungsten carbide substrate with a metallic solder is another way of producing diamond tools. During machining operation, the diamond wafer will behave similarly to the PCD insert but without the presence of the metallic binder in the region in contact with the workpiece. This region usually reaches high temperatures and the presence of the binder would increase the wear rate of the PCD tool compared to the CVD brazed tool. Moreover, the rough growing side of the diamond wafer can be brazed in contact with the tungsten carbide substrate, while the smooth wafer side would act as the cutting tool surface, producing a small surface roughness of the workpiece. The adhesion strength of the brazed tool can be optimized by choosing the appropriate solder and brazing conditions, and there is no need to pretreat the tungsten carbide substrate before brazing.

Belmonte et al. ${ }^{3}$ compared the wear resistance of these three types of diamond tools during turning of sintered hardmetals, and their results show that the performance of the brazed tool is superior. 
Nowadays it is possible to grow thick CVD diamond wafers with large area at relatively low cost. Brazing as a method of joining metals is known for hundreds of years, and consists of using a low melting point metal to bond two metallic components ${ }^{4}$. However, the chemical inertness of diamond requires the use of special solders for brazing, containing a small amount of transition elements which actively react with carbon. This reactivity would be responsible for the joining of the diamond wafer to the tungsten carbide substrate. Metallic alloys containing $\mathrm{Ag}-\mathrm{Cu}$ and a small concentration of Ti has been used to braze diamond films $\mathrm{s}^{3,4}$. The Ti atoms are responsible for the reactivity with both diamond and tungsten carbide through the $\mathrm{TiC}$ formation $^{5}$. However, due to the strong reactivity of Ti with oxygen, the brazing procedure has to be performed under vacuum or inert atmosphere and high temperature. The brazing filler should also remain ductile and reduce the thermal stress between the diamond wafer and the substrate ${ }^{3}$. The carbide formation induced by the Ti active atoms will depend on their diffusivity under the brazing conditions and, therefore, the adherence strength will depend on the brazing atmosphere, temperature and time.

The indentation and scratch tests, conventionally used to evaluate the adhesion strength of thin diamond films deposited over tungsten carbide substrates ${ }^{6-8}$, are not suitable for brazed tools due to the large thickness of the diamond wafer. Recently, Sun et al..$^{5}$ evaluated the bonding strength of CVD diamond films brazed on WC-Co (8\%) substrates with Ag-Cu-Ti alloy using a shear strength test. They concluded that the brazing temperature, in the range of 850 to $970{ }^{\circ} \mathrm{C}$, does affect the shear strength of the joint and the Ti active element is the most important factor responsible for the joining through the $\mathrm{TiC}$ formation at the interfaces.

In this work we brazed diamond wafers $(\sim 0.5 \mathrm{~mm})$ over WC-Co (6\%) substrates with a Ag-Cu-Ti $(8 \%)$ solder (0.1 mm thick), at temperatures from 800 to $980^{\circ} \mathrm{C}$, during 3 to $40 \mathrm{~min}$. We adapted a tensile strength test to evaluate the adhesion strength as a function of the brazing temperature and time and we analyzed the fractured surfaces by optical microscopy.

\section{Experimental Method}

\subsection{Brazing procedure}

The diamond wafer $(0.5 \mathrm{~mm}$ thick and $5 \mathrm{~cm}$ diameter) was grown by microwave plasma deposition over a silicon substrate at the Laboratório de Altas Pressões e Materiais Avançados (LAPMA) of the Instituto de Física-UFRGS. After removing the silicon substrate by chemical etching, the diamond wafer was cut into small disks of about $4 \mathrm{~mm}$ diameter with a high power Nd:YAG pulsed laser. The shape of the tungsten carbide (K-10 type) substrates was conveniently chosen to adapt them to the tensile strength test: they were cylinders $30 \mathrm{~mm}$ long with $4 \mathrm{~mm}$ diameter. The surface facing the diamond disk was previously polished. Fig. 1 shows the brazing assembly, kept in the vertical position inside a ceramic holding support and submitted to a small pressure on the top by a weight of $0,165 \mathrm{~kg}$.

During the brazing procedure, this set was placed inside a silica tube with $32 \mathrm{~mm}$ diameter, connected to a vacuum system $\left(10^{-4}\right.$ torr $)$. The heating rate of the system under vacuum, inside a tubular furnace, was $15^{\circ} \mathrm{C} / \mathrm{min}$ up to the selected brazing temperature. After heating during the desired holding time, the system was cooled under vacuum down to $400{ }^{\circ} \mathrm{C}$, and ventilated down to the room temperature.

\subsection{Tensile Strength Test}

Figure 2 shows the experimental setup used to evaluate the adhesion strength between the diamond wafer and the
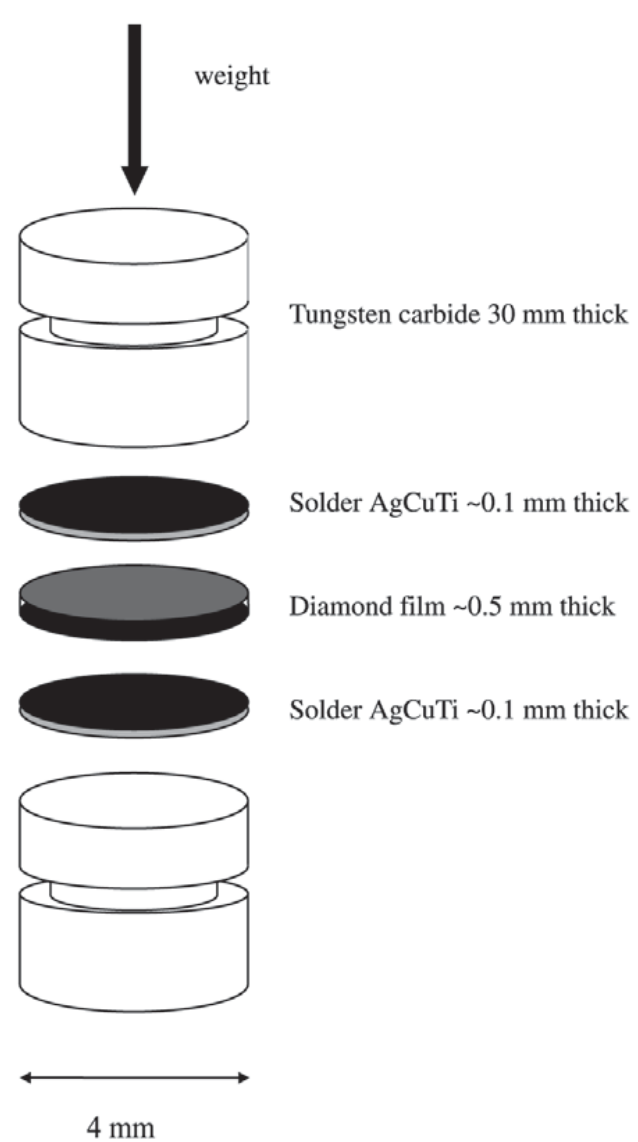

Figure 1. Schematic view of the brazing assembly appropriate to the tensile strength test. 


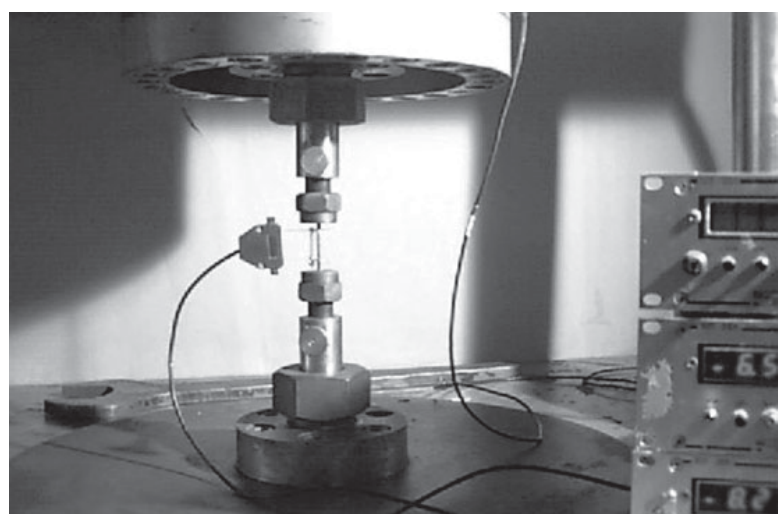

Figure 2. Experimental setup for the tensile strength test.

tungsten carbide through the tensile strength test. The tests were performed in the Laboratório de Ensaios Mecânicos GEFMAT - FURG, using a mechanical apparatus from WERKSTOFFPRUFMASCHINEN LEIPZIG. It was designed and constructed a special system to hold the sample during the test to avoid damaging the machine due to the high hardness of the tungsten carbide. The indent in the tungsten carbide cylinders represented in Fig. 1 (2 mm width and $0,6 \mathrm{~mm}$ depth) was used to clip the brazed samples into the machine during the test. The calibration of the load cell and of the clip gauge in the same apparatus enabled the use of its own acquisition data system to register the experimental data.

The tensile strength test consisted in increasing the load applied through the clips of the machine on the opposite cylinders of the brazed assembly up to the failure. The maximum load supported by the assembly before failure was registered and the fractured surfaces were analyzed by optical microscopy. The failure strength $\left(\sigma_{\text {failure }}\right)$ was considered to be given by the ratio of the maximum load and the effective brazed area.

\section{Results and Discussion}

In the literature, Sun et al. ${ }^{5}$ present results about the adhesion strength of diamond films brazed on hard metal using the $\mathrm{Ag}-\mathrm{Cu}-\mathrm{Ti}$ system alloy at temperatures from 850 to $970{ }^{\circ} \mathrm{C}$ during $20 \mathrm{~min}$. The diamond wafer was $110 \mu \mathrm{m}$ thick, the filler metal was $30 \mu \mathrm{m}$ thick and the adhesion was evaluated by a shear strength test. In the present work the adhesion strength was evaluated as a function of the brazing temperature, in the range from $800^{\circ} \mathrm{C}$ to $980^{\circ} \mathrm{C}$, and as a function of the brazing time, from 3 to $40 \mathrm{~min}$, by a tensile strength test. The diamond wafer was about $500 \mu \mathrm{m}$ thick and the filler metal was $100 \mu \mathrm{m}$.

The results showed that the minimum temperature re- quired to successfully braze the diamond film on hard metal is $850{ }^{\circ} \mathrm{C}$ during at least $20 \mathrm{~min}$. The heating up to $800{ }^{\circ} \mathrm{C}$ induces the melting of the metallic solder but the reactivity at the interface was not enough to promote the adhesion

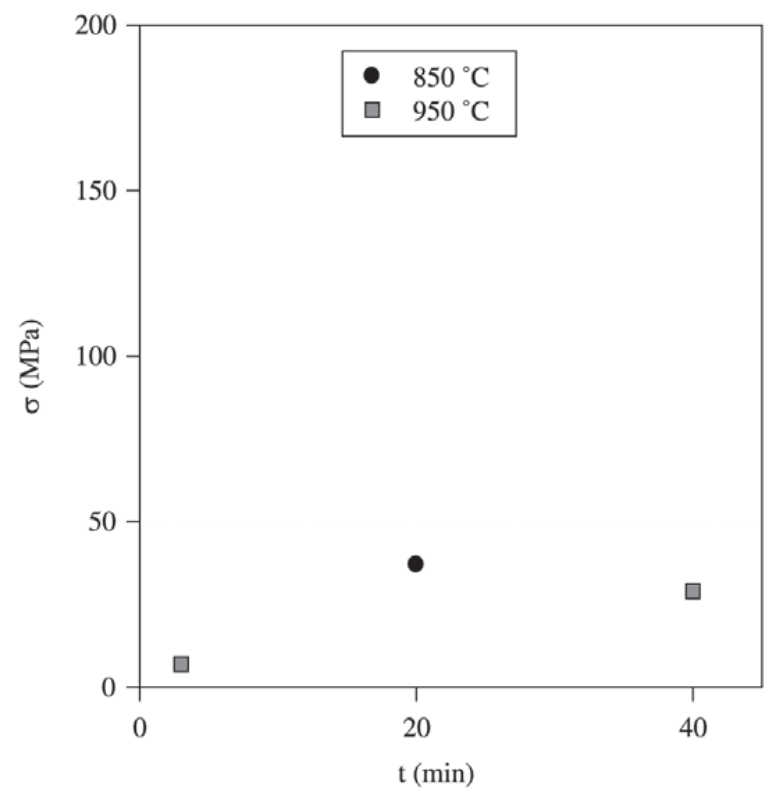

(a)

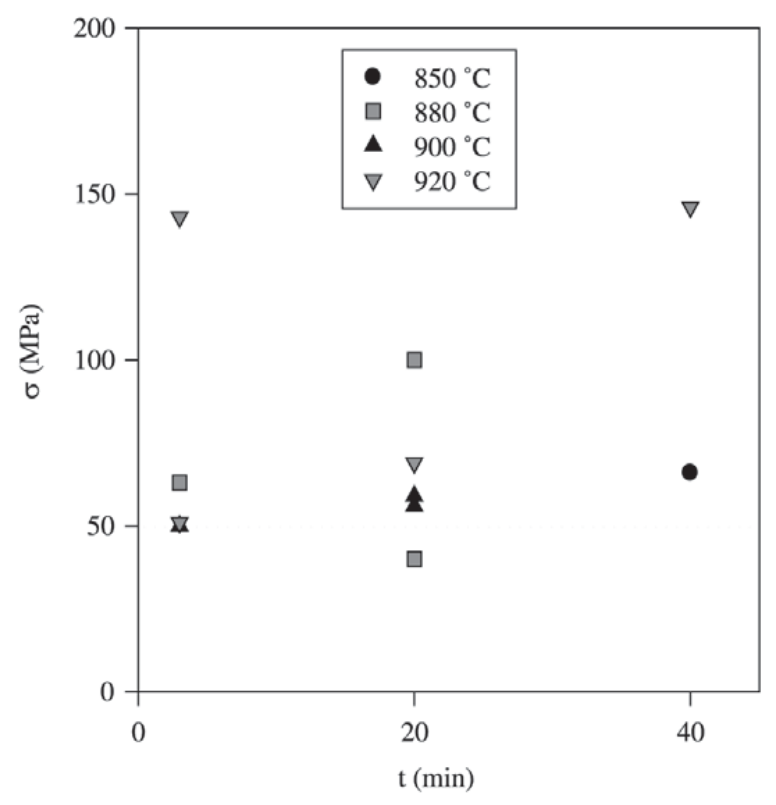

(b)

Figure 3. Failure strength as a function of the brazing time for distinct brazing temperatures, as indicated. a) Fracture occurred at the interface between diamond and solder; (b) Fracture occurred along the diamond wafer thickness. 
between the film and the substrate, even after $40 \mathrm{~min}$ processing. On the other hand, the brazing was accomplished at $880{ }^{\circ} \mathrm{C}$ after $3 \mathrm{~min}$ processing.

The optical analysis of the fractured surfaces after the tensile strength test revealed that, in some cases, the diamond wafer cracked paralel to its surface for distinct braz-

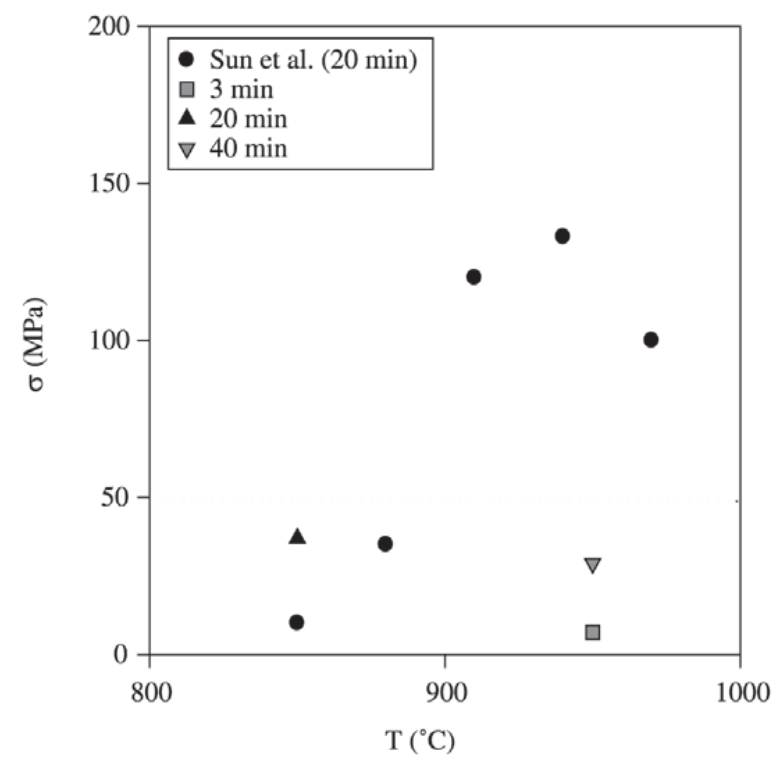

(a)

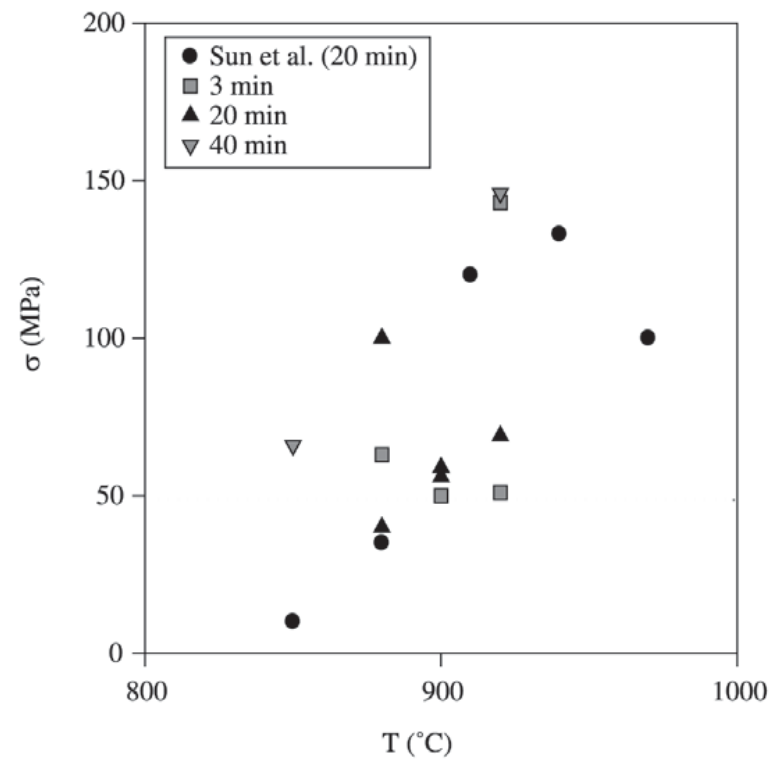

(b)

Figure 4. Failure strength as a function of the brazing temperature for distinct holding times, as indicated. a) Fracture occurred at the interface between diamond and solder; b) Fracture occurred along the diamond wafer thickness. ing temperatures and holding times. In these cases, the adhesion strength between the diamond wafer and the tungsten carbide substrate was probably higher than the intrinsic diamond film strength. Figures 3 and 4 show the results for the failure strength as a function of the brazing holding time and temperature, respectively. It is important to remark that the effective brazing area did not necessarily correspond to the total surface area of the tungsten carbide cylinder. The wettability of the solder along the interface depends on the brazing temperature and time. Thermal gradients and non-uniform contact pressure were probably responsible for the observed heterogeneous behavior. For each sample it was necessary to estimate, by optical microscopy analysis, the effective brazing area. The cases where this area was smaller than $70 \%$ of the surface area were discarded because a high strength related to a small brazed area would not be useful for application in cutting tools. Figure 5 shows a SEM image of the fractured surfaces.

Figures $3 \mathrm{~b}$ and $4 \mathrm{~b}$ show the strength measured for those samples where the wafer cracked along its thickness during the tensile test while the interface region between the wafer

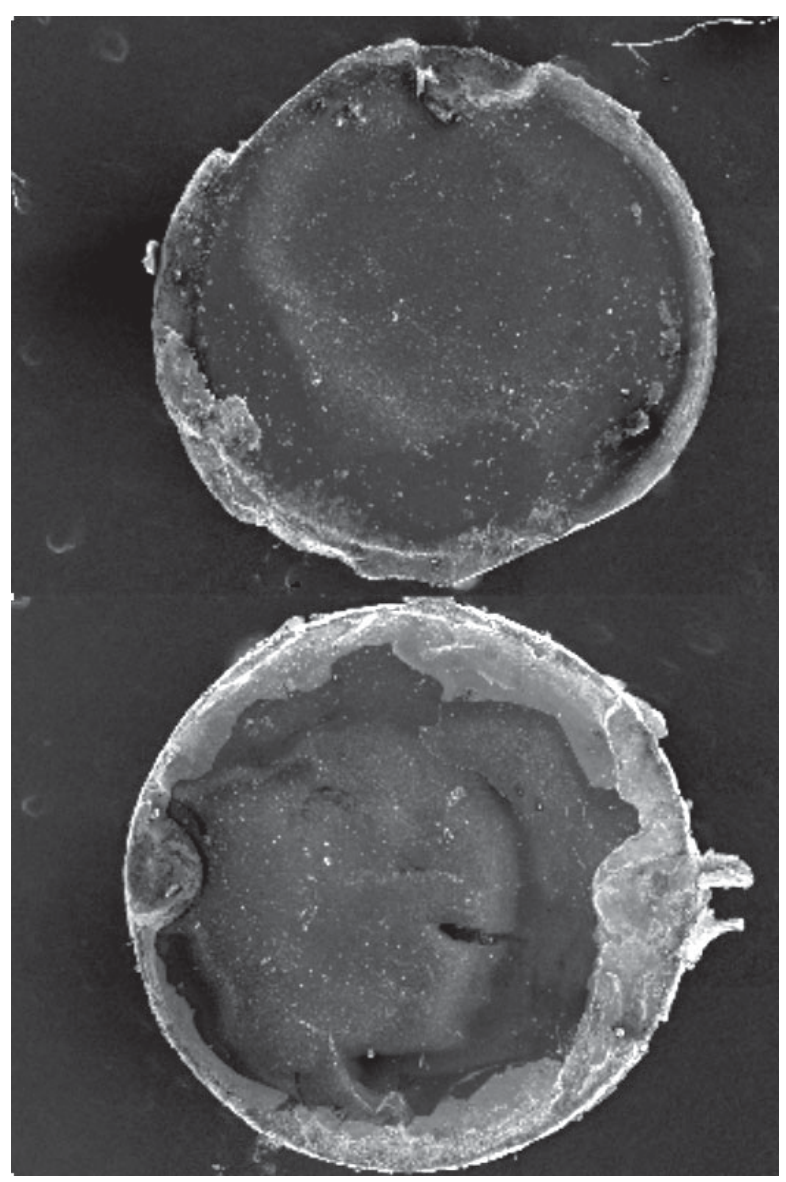

Figure 5. SEM image of the top view of the fractured surface. 
and the tungsten carbide remained brazed. These values are related to the intrinsic strength of the diamond film itself. As can be seen in these figures, they ranged from 50 to 150 $\mathrm{MPa}$, depending on the temperature and holding times. The results shown in Fig. 3a and 4a correspond to the brazing conditions where the fracture occurred at the joining interface. In these cases, the brazing strength was low, smaller than $50 \mathrm{MPa}$, indicating that the respective brazing conditions were not appropriate. At these conditions, corresponding to temperatures higher than $920^{\circ} \mathrm{C}$, the thickness of the fragile carbide layer at the interface is probably large, decreasing the adhesion strength.

For comparison, the results of Sun et al..$^{5}$ are also shown in Fig. 4, despite they did not mention where the fracture occurred during the shear strength test. The agreement is quite good and suggests that the adhesion strength is not strongly dependent on the wafer and solder thickness, neither on the evaluation test, but on the carbide formation at the interface.

\section{Conclusions}

The tensile strength test showed to be adequate to evaluate the adhesion strength of the diamond wafer brazed on hard metal. However, the reliability of the results is related to the determination of the effective brazing area, that does not necessarily correspond to the surface area of the wafer. The adherence depends on the brazing temperature and time, probably because the kinectics controlling the diffusion and reactivity of the metallic solder with the diamond wafer and with the tungsten carbide strongly depend on these parameters, resulting in the $\mathrm{TiC}$ formation at the interface. It is possible to obtain good adherence for brazing temperatures as low as $850^{\circ} \mathrm{C}$ but the brazing time must be at least $20 \mathrm{~min}$. For temperatures higher than $920^{\circ} \mathrm{C}$, the adhesion strength decreases, probably due to the increasing thickness of the fragile carbide layer at the interface. The best results were obtained for brazing temperatures from 880 to $920^{\circ} \mathrm{C}$, independently of the holding time, from 3 to $40 \mathrm{~min}$.

\section{Acknowledgments}

The authors would like to thank to the undergraduate students Henrique Gontow and João Gari da Silva Fonseca Jr. (BIC/FAPERGS) for their help with the sample preparation and brazing process, and to the finnancial support from PRONEX/MCT, PADCT III/CNPq, PGCIMAT/UFRGS and FAPERGS from Brazil.

\section{References}

1. Chen, M.; Sun, F.; Zhang, Z. Key Engin. Mater., v. 196, n. 193-198, 2001.

2. Tribology Series, 28, D. Dowson, Coating Tribology: Properties, Techniques and Applications in Surface Engineering, by K. Holmberg and A. Matthews, Elsevier, 1994.

3. Belmonte, M.; Ferro, P.; Fernandes, A.J.S.; Costa, F.M.; Sacramento, J.; Silva, R.F. Diamond Relat. Mater, v. 12, p. 738-743, 2003.

4. Benz, E. Industr. Diamond Rev., v. 51, p. 249-250, 1991.

5. Sun, J.; Feng, D.; Li, J. Mat. Proc. Techn., v. 115, p. 333337, 2001.

6. Jindal, P.C.; Quinto, D.T.; Wolfe, G.J. Thin Sol. Films, v. 154 , p. 361-375, 1987.

7. Nesládek, M.; Vandierendonck, K.; Quaeyhaegens, C.; Kerkhofs, M.; Stals, L.M. Thin Sol. Films, v. 270, p. 184188, 1995.

8. Zalavutdinov, R.K.; Gorodetsky, A.E.; Zakharov, A.P.; Lakhotkin, Y.V.; Ralchenko, V.G.; Samokhvalov, N.V.; Anikin, V.N.; Pjyanov, A.I. Diam. Relat. Mater., v. 7 , p. 1014-1016, 1998. 
